\title{
АКТУАЛЬНЫЙ BOПРОC
}

Канунникова Н.Г.

\section{ПРОБЛЕМЫ ВИДОВОЙ КЛАССИФИКАЦИИ АДМИНИСТРАТИВНО-ПРАВОВЫХ ОТНОШЕНИЙ}

Аннотация. В статье рассматриваются некоторые вопросы, касающиеся теоретических воззрений на проблемы видовой классификации административно-правовых отношений, представлена характеристика различных подходов ученых-административистов, занимающихся проблемами административного права. Актуальность тематики статьи определена важностью исследуемого правового института, поскольку мобильность административно-правовых отношений порождает их большой количественный состав, что позволяет говорить о более глубоком исследовании и изыскании новых научных подходов к видовой классификации этих отношений, разработанной наукой административного права, но исследованной не в достаточно полной мере.Объектом исследования, проведенного в рамках статьи, выступают общественные отношения, регулируемые наукой административного права, предметом - теоретические подходы к определению видовых классификаций исследуемых в статье административно-правовых отношений. Основываясь на положениях всеобщего диалектического метода познания социальных явлений, а также, используя такие научные методы исследования как: системный, структурно-функциональный, научно-аналитический, сравнительного анализа, автор предлагает свое видение новых классификационных признаков административно-правовых отношений сточки зрения научности, анализа, сравнения и логики. Основным выводом проведенного в данной статье исследования является предлагаемый автором новый вид административно-правовых отношений, основу которого составляет поведенческий фрактор участника исследуемых отношений (объективные и субъективные правоотношения), диктуемый правомерными и неправомерными действиями: правомерными действиями - объективные правоотношения, неправомерными действиями - субъективные правоотношения.

Ключевые слова: административное право, административно-правовые отношения, вид, классификация, множественность, ученые-административисты, правомерное поведение, неправомерное поведение, объективные правоотношения, субъективные правоотношения.

Abstract. The article considers some issues, related to theoretical views on the problems of classification of administrativelegal relations and demonstrates the characteristic of various approaches of scholars, studying the problems of administrative law. The topicality of this issue is determined by the importance of the legal institution under consideration, since the mobility of administrative-legal relations determines their numerical composition, that allows speaking about a more comprehensive study and search for the new scientific approaches to the classification of these relations, developed by the administrative law science, which hasn't been studied sufficiently enough. The research object is social relations, regulated by the administrative law science; the research subject includes the theoretical approach to the definition of classifications of social-legal relations. Based on the provisions of the general dialectical method of cognition and the system, structural-functional, scientific-analytical methods and comparative analysis, the author offers her own vision of the new classificatory features of administrative and legal relations from the position of the scientific character, analysis, comparison and logic. The author introduces the new type of administrative-legal relations, based on the behavioral factor of a participant of relations (objective and subjective legal relations), conditioned by legal and illegal actions: legal actions include objective legal relations, illegal actions include subjective legal relations.

Key words: subjective legal relations, objective legal relations, illegal behavior, legal behavior, scholars in the field of administrative law, multiplicity, classification, type, administrative-legal relations, administrative law.

$\mathrm{T}$ еоретические аспекты административноправовых отношений уже выступали объектом исследования автора[1, с. 130-133]. Кроме того, в своих работах ею неоднократно отмечалось существенное многообразие сферы го- сударственного управления[2 - 3], что порождает различные по своему характеру, содержанию и направленности административно-правовые отношения, складывающиеся в пределах данной сферы. Мобильность административно-право- 
вых отношений порождает их большой количественный состав, что позволяет говорить о более глубоком исследовании и изыскании новых научных подходов к видовой классификации этих отношений, разработанной наукой административного права, но исследованной не в достаточно полной мере.

Разработкой проблем административно-правовых отношений занимались ряд ученых-административистов[4 - 8]. Значительное внимание проблеме видовой классификации административно-правовых отношений, по мнению автора, уделил Ю.М. Козлов[9, с. 72], который разделил их на:

1. Основные и неосновные;

2. Внешние и внутриорганизационные;

3. Субординационные и координационные;

4. Вертикальные и горизонтальные.

К основным административно-правовым отношениям ученый относит властеотношения, которые обязательны в управленческой сфере. Неосновные отношения представлены отношениями, возникающими между участниками, не находящимися в организационной подчиненности друг у друга, т.е. между равноправными участниками.

Специфика внешних административно-правовых отношений заключается в их возникновении в рамках внешней сферы управления, т.е. непосредственно в процессе реализации функций управления применительно к управляемым объектам. Внутриорганизационные отношения возникают в рамках внутренней деятельности органов управления (распределение функциональных обязанностей между сотрудниками управленческого аппарата, определение их ответственности и т.п.).

Для субординационных отношений Ю.М. Козлов, в качестве характерной составляющей, определяет авторитарность (властность) юридических волеизъявлений субъекта управления. В координационных административно-правовых отношениях заложены, по мнению автора, такие управленческие связи, в которых авторитарность отсутствует (отношения между несоподчиненными исполнительными органами).

Вертикальные административно-правовые отношения возникают между участниками, находящимися в организационной подчиненности друг у друга и исключают равенство сторон. Властной стороной в них всегда выступает соответствующий исполнительный орган, чей объем юридически-властных полномочий больше по сравнению со второй стороной правоотношения (например, Правительство и министерство), либо вторая сторона вообще не имеет таких полномочий (например, гражданин).
В качестве горизонтальных правоотношений автор выделяет отношения между фактически и юридически равноправными сторонами.

Разработкой проблем видового деления административно-правовых отношений занимался Д.М. Овсянко[10, с. 99], который в качестве классификационного критерия идентичности административно-правовых отношений предлагал:

1) характер взаимоотношений участников правоотношений;

2) цели правоотношений;

3) содержание правоотношений;

4) способ защиты правоотношений.

По характеру взаимоотношений участников правоотношений автор выделял:

- вертикальные (субординационные) правоотношения, возникающие между соподчиненными сторонами, когда существует приоритет субъекта управления в системе органов исполнительной власти;

- горизонтальные (координационные) правоотношения, в рамках которых стороны равноправны, не подчинены друг другу в системе органов исполнительной власти;

- правоотношения, возникающие между органами исполнительной власти и не подчиненными им участниками отношений, не относящимися к системе органов исполнительной власти (негосударственные организации, физические лица и др.).

По целям правоотношений (их предназначению) Д.М. Овсянко выделяет внешние и внутренние управленческие отношения, критерий деления которых аналогичен критерию деления, предлагаемому Ю.М. Козловым.

Содержание правоотношений Д.М. Овсянко определяет их материальной, процессуальной и договорной природой.

По способу защиты административно-правовых отношений автор выделяет правоотношения, защищаемые:

- в административном порядке;

- в судебном порядке.

Как видим, в указанном выше перечне значатся различные по своей правовой природе, характеру и критериям виды административно-правовых отношений. Тем не менее, автор считаем, что можно выделить еще один вид административно-правовых отношений, в основу которого будет заложено поведение участников этих отношений, т.е. - правоотношения, порождаемые правомерными и неправомерными действиями.

Административные правоотношения, порождаемые правомерными действиями, можно назвать объективными правоотношениями. Объ- 


\section{Административное и муниципальное право 12 (108) 2016}

ективные правоотношения возникают на основе норм административного права и строго им соответствуют.

Административные правоотношения, порождаемые неправомерными действиями, автор пред- лагает назвать субъективными правоотношениями, возникающими вследствие неправомерного поведения участников административно-правового отношения, как реакция общества и государства на такое поведение.

\section{Библиография:}

1. Канунникова Н.Г. Теоретические аспекты административно-правовых отношений / ж. Пробелы в российском законодательстве. Вып.6. 2016. С.130-133.

2. Канунникова Н.Г. Эволюция управления и современные подходы к определению его понятия. Социальное управление / ж. Административное право и процесс. 2012. № 9. С. 20-25.

3. Канунникова Н.Г. К вопросу о предмете административного права / ж. Административное право и процесс. 2012. № 7. C. 22-25.

4. Алехин А.П., Кармолицкий А.А., Козлов Ю.М. Административное право Российской Федерации. М., 1997. С. 60-67.

5. Административное право России: курс лекций / Под ред. проф. Н.Ю. Хаманевой. М., 2007. С. 105-117.

6. Агапов А.Б. Административное право. М., 2004. С. 32-42; Бахрах Д.Н., Россинский Б.В., Старилов Ю.Н. Административное право. М., 2005. С. 105-116.

7. Габричидзе Б.Н., Чернявский А.Г. Административное право Российской Федерации. М., 2001. 624 с.

8. Тихомиров Ю.А. Курс административного права и процесса. М., 1998. С. 376-399.

9. Козлов Ю.М. Административное право. М., 2001. С. 72.

10. Овсянко Д.М. Административное право. М., 2000. С. 99.

\section{References (transliterated):}

1. Kanunnikova N.G. Teoreticheskie aspekty administrativno-pravovykh otnoshenii / zh. Probely v rossiiskom zakonodatel'stve. Vyp.6. 2016. C.130-133.

2. Kanunnikova N.G. Evolyutsiya upravleniya i sovremennye podkhody k opredeleniyu ego ponyatiya. Sotsial'noe upravlenie / zh. Administrativnoe pravo i protsess. 2012. № 9. S. 20-25.

3. Kanunnikova N.G. K voprosu o predmete administrativnogo prava / zh. Administrativnoe pravo i protsess. 2012 . № 7. S. 22-25

4. $\quad$ Alekhin A.P., Karmolitskii A.A., Kozlov Yu.M. Administrativnoe pravo Rossiiskoi Federatsii. M., 1997. S. 60-67.

5. Administrativnoe pravo Rossii: kurs lektsii / Pod red. prof. N.Yu. Khamanevoi. M., 2007. S. 105-117.

6. Agapov A.B. Administrativnoe pravo. M., 2004. S. 32-42; Bakhrakh D.N., Rossinskii B.V., Starilov Yu.N. Administrativnoe pravo. M., 2005. S. 105-116.

7. Gabrichidze B.N., Chernyavskii A.G. Administrativnoe pravo Rossiiskoi Federatsii. M., 2001. 624 s.

8. Tikhomirov Yu.A. Kurs administrativnogo prava i protsessa. M., 1998. S. 376-399.

9. Kozlov Yu.M. Administrativnoe pravo. M., 2001. S. 72.

10. Ovsyanko D.M. Administrativnoe pravo. M., 2000. S. 99. 